\title{
Assessing Risk Behaviors and Prevalence of Sexually Transmitted and Blood-Borne Infections among Female Crack Cocaine Users in Salvador - Bahia, Brazil
}

\author{
Ceuci L.X. Nunes ${ }^{1}$, Tarcisio Andrade ${ }^{2}$, Bernardo Galvão-Castro ${ }^{1,3}$, Francisco I. Bastos ${ }^{4}$ and Arthur Reingold $^{\mathbf{5}}$ \\ ${ }^{1}$ Bahiana School of Medicine - Bahiana Foundation for Science Development; ${ }^{2}$ School of Medicine - Federal University of Bahia / Center for \\ the Study and Treatment of Drug Abuse; ${ }^{3}$ Gonçalo Muniz Research Center/Oswaldo Cruz Foundation (FIOCRUZ), Salvador, BA; ${ }^{4}$ Oswaldo \\ Cruz, Foundation (FIOCRUZ), Rio de Janeiro, RJ, Brazil; ${ }^{5}$ Department of Epidemiology, School of Public Health, University of California at \\ Berkeley, USA
}

\begin{abstract}
Crack cocaine use is associated with risky sexual behaviors and sexually transmitted infections (STIs), including HIV. We investigated sociodemographic and behavioral characteristics and infection rates in female crack cocaine users from impoverished communities of Salvador, Bahia, Brazil. A sample of 125 female crack cocaine users was recruited. Overall, the interviewees had low educational level and high rate of unemployment (close to $90 \%$ ). Onethird $(37 \%)$ reported having traded sex for money or drugs, and $58 \%$ reported that they had not used condoms during intercourse in the last 30 days. The prevalence of infections was low: HIV-1.6\%; HCV-2.4\%; HBV- 0.8\%; HTLV I/II4.0\%; and syphilis-4.0\%. The combination of dire poverty and high prevalence of risk behaviors turn such populations a preferential target of initiatives aiming to reduce drug-related harm and promote social development. Low infection rates should not be viewed with complacency, but as a window of opportunity to implement prevention initiatives and reduce social marginalization.
\end{abstract}

Key-Words: Risk behaviors, prevalence of sexually transmitted and blood-borne infections, female crack cocaine users.

A significant increase in the number of AIDS cases among women has been reported worldwide: women currently account for $50 \%$ of all HIV/AIDS cases worldwide and $30 \%$ of cases in Latin America [1]. In Brazil, reports of female AIDS cases increased $75.3 \%$ between 1994 and 1998, while reports of male cases increased by only $10.2 \%[2,3]$.

In parallel with the HIV/AIDS epidemic, crack cocaine use has increased dramatically across the world since its introduction in the USA in the 1980's, mainly in deprived neighborhoods of metropolitan areas [4-9].

In São Paulo, Brazil, the first crack cocaine-related arrest occurred in 1991 [10]. By 1993, a study targeting street children in Sao Paulo (Southeast Brazil) found that 36\% reported having ever used crack and $11 \%$ reported daily use [11]. Initially, crack use was less prevalent in Northeast Brazil: in 1993, not a single patient attending the main reference center for drug users in the State of Bahia (CETAD: Centro de Estudos e Terapia do Abuso de Drogas - Center for Research and Treatment of Drug Abuse, affiliated with the Federal University of Bahia) reported having ever used crack cocaine. However, the proportion of patients attending CETAD who reported having used crack increased from 4\% in 1996 to $40 \%$ in 1998. In 2002, CETAD provided 13,807 consultations to drug users; $43 \%$ of these were women, and nearly $30 \%$ of these women reported having smoked crack.

Numerous studies have demonstrated an association between crack cocaine use and high rates of infection with

Received on 4 July 2007; revised 22 October 2007.

Address for correspondence: Dr. Ceuci L.X. Nunes. Couto Maia Hospital. Rua Rio São Francisco s/n ${ }^{\circ}$, Zip code: 40425060 Monte Serrat. Salvador, BA, Brazil. Phone: 71 33163085. Fax: 71 33163467. E-mail: ceuci@uol.com.br com cópia para bgalvao@cpqgm.fiocruz.br.

The Brazilian Journal of Infectious Diseases 2007;11(6):561-566. (C) 2007 by The Brazilian Journal of Infectious Diseases and Contexto Publishing. All rights reserved.
HIV and other STIs, especially among injecting drug users who are exposed to both parenteral and sexual risks [8,12-19]. Other studies have shown that female crack cocaine users engage in risky sexual behaviors that increase the risk of contracting STIs (e.g. multiple sexual partners, unprotected oral, vaginal and anal sex) more frequently than male crack cocaine users. Trading sex for money or drugs is a key factor implicated in STI transmission in this group [13,20-31]. Greater numbers of sexual partners, use of crack before and during intercourse, and unprotected sex are also associated with a high risk of STIs in users who trade sex for drugs or money $[17,27]$. Female crack cocaine users also complain about depression, anxiety and loneliness $[13,15]$. Some authors have reported an increased risk of oral HIV transmission associated with labial and oral injuries caused by the pipes used for smoking crack [5,32]. A study of 1,723 American women showed a relationship between the intensity and frequency of crack cocaine use and risky sexual practices and HIV infection [32]. Crack cocaine use has been directly associated with gonorrhea, syphilis, chancroid and other STIs in several studies [16,33-35]. Crack cocaine use is also a risk factor for the acquisition of STIs in HIV patients who continue to practice risky sexual behavior while under care in drug abuse treatment units $[17,33,36]$.

The reported prevalence of HIV infection among crack cocaine users ranges widely. In a study carried out by the National Institute of Drug Abuse (NIDA) in 17 American cities, the prevalence ranged from $0.0 \%$ in Tucson, Arizona, to $23.3 \%$ in Miami, Florida; the overall prevalence was $6.5 \%$ among men and $9.1 \%$ among women [13]. In another study, the prevalence of HIV infection among female crack cocaine users was 2.0\% in San Francisco, California, 23\% in Miami, Florida, and $29.6 \%$ in New York [5].

The purposes of this study were to estimate the prevalences of blood-borne and sexually transmitted diseases 
in female crack cocaine users from Salvador, and to identify risk factors for infection.

\section{Material and Methods}

During a six month recruitment period (October 2001 to April 2002), CETAD outreach workers recruited a total of 125 female crack cocaine users from three low-income neighborhoods. We stopped at 125 participants because of time and budget limitations. The trained outreach workers lived in the targeted communities. We chose these three neighborhoods because they are typical low-income neighborhoods and because they are the core neighborhoods targeted by the different "harm-reduction" initiatives implemented in the city. Although these neighborhoods have high rates of unemployment, the neighborhoods themselves are not centers of drug trafficking or prostitution. Known female crack users were contacted and informed of the study objectives. The enrollment criteria were: reported crack cocaine use in the last six months, age $\geq 18$ years and capacity to understand and sign the informed consent form. Those who agreed to participate and signed the informed consent form were interviewed at the CETAD outpatient unit in a private room. Trained interviewers administered a questionnaire concerning demographic, behavioral and clinical characteristics. After the interview, each subject received a clinical examination, and $20 \mathrm{~mL}$ of blood sample were obtained for serological testing. Each interviewee received the equivalent of US\$ 4.00 for transportation and a snack. Women who had any disease manifestations were referred to specific health services.

Serological tests were performed at the Advanced Public Health Laboratory (Gonçalo Muniz Research, Oswaldo Cruz Foundation/FIOCRUZ, Bahia). Ortho Diagnostics EIA test kits (New Jersey, USA) were used for detecting HIV and HTLV; all samples positive for HIV were confirmed by indirect fluorescent antibody, while HTLV-1 and HTLV-2 were confirmed by Western blot (Genelabs 2.4, Singapore). Hepatitis $\mathrm{C}$, hepatitis B, and syphilis were detected and confirmed with the UBI HCV 4.0 test kit (Beijing, China), the Bio Rad EIA HbsAg kit (Marnes La Coquette, France), and VDRL (Wiener Llab, Rosário, Argentina), respectively.

SPSS software for Windows (version 11.0) was used for data entry, as well as for obtaining frequencies, means, and standard deviations.

The study protocol was approved by the University Hospital Ethics Research Committee (School of Medicine, Federal University of Bahia) and the Committee for the Protection Human Subject at the University of California, Berkeley.

\section{Results}

None of the women contacted in the communities refused participation in the study; however, two denied having smoked crack in the last six months and were excluded, yielding a final number of 125 female crack users.
Basic sociodemographic and behavioral information are shown in Table 1. The mean age of the women was 22.5 ( \pm 6.2) years. In addition, $91.2 \%$ described themselves as African-descendents; $2 \%$ were illiterate and $87 \%$ had less than eight years of education, although 40 women $(33.6 \%)$ reported that they were currently attending school. Sixtythree women $(50.4 \%)$ reported having a profession; the vast majority of them $(79.3 \%)$ defined themselves as housekeepers, with a miscellanea of other low-paid jobs such as manicurist, caretaker, small trader, elementary school teacher, craftswoman and health ancillary personnel. Seventy women $(56 \%)$ were unemployed at the time of the interview. Sixty-one women $(48.8 \%)$ were married or were living with a partner; while two $(1.6 \%)$ were separated and $62(49.6 \%)$ were single.

Table 1. Demographic and behavioral features of the 125 female crack users recruited for the study, Salvador, Bahia 2001-2002

\begin{tabular}{|c|c|}
\hline \multicolumn{2}{|l|}{ Demographic data } \\
\hline Age(mean) & $22.5 \pm 6.2$ \\
\hline \multicolumn{2}{|l|}{ Race(self identified) } \\
\hline Afro-descendents & $114 / 125(91.2 \%)$ \\
\hline Others & $11 / 125(8.8 \%)$ \\
\hline \multicolumn{2}{|l|}{ Educational background } \\
\hline Illiterate & $2 / 125(1.6 \%)$ \\
\hline Less than eight years of education & $111 / 125(87.6 \%)$ \\
\hline \multicolumn{2}{|l|}{ Prior Occupations } \\
\hline Have a profession & $63 / 125(50.4 \%)$ \\
\hline Housekeeper & $50 / 63(79.3 \%)$ \\
\hline Others & $13 / 63(20.7 \%)$ \\
\hline \multicolumn{2}{|l|}{ Monthly Income } \\
\hline Median (reais) & $151.90 \pm 84.45$ \\
\hline$\leq$ one minimum wage & $93 / 107(86.9 \%)$ \\
\hline Have Children (yes) & $92 / 125(73.6 \%)$ \\
\hline \multicolumn{2}{|l|}{ Behavioral data } \\
\hline Lifetime number of sexual partners (mean) & $\begin{array}{l}10.9 \pm 12.8 \\
\text { (range } 1 \text { to over } 100)\end{array}$ \\
\hline Lifetime number of sexual partners among & $22.4+21.1$ \\
\hline $\begin{array}{l}\text { women who traded sex for money or } \\
\text { drugs in the last six months (mean) }\end{array}$ & $*_{p}<0.005$ \\
\hline \multicolumn{2}{|l|}{ Age at first sexual intercourse: } \\
\hline$\leq 14$ years & $83 / 124(66.9 \%)$ \\
\hline \multicolumn{2}{|l|}{ Use of condoms in the 30 days before: } \\
\hline Did not use condoms & $75 / 124(58 \%)$ \\
\hline $\begin{array}{l}\text { Did not carry condoms or kept } \\
\text { condoms at home }\end{array}$ & $65 / 124(52.4 \%)$ \\
\hline \multicolumn{2}{|l|}{ Trading sex for money or drugs: } \\
\hline Lifetime & $46 / 125(36.8 \%)$ \\
\hline In the last six months & $23 / 125(18.4 \%)$ \\
\hline Before 17 years of age & $34 / 46(73.9 \%)$ \\
\hline $\begin{array}{l}\text { Never had an injecting drug user } \\
\text { sex partner }\end{array}$ & $75 / 125(60.0 \%)$ \\
\hline
\end{tabular}


Ninety-two women (73.6\%) had given birth to at least one child and $76 \%$ reported having had only one sexual partner in the last 30 days. The mean reported monthly income was $\mathrm{R} \$$ $151.90( \pm 84.45)$, roughly US\$ $43.40( \pm 24.1)$, and the vast majority $(86 \%)$ of interviewees reported receiving less than one Brazilian minimum wage per month (R\$ 200.00, approximately US\$ 65.00). Just over two-thirds of the interviewees ( 83 of 124) reported first sexual intercourse prior to age 14 . The total number of lifetime sexual partners ranged from 1 to over 100, with a mean of $10.9( \pm 12.8)$ and a median of seven lifetime partners. The mean number of lifetime partners was significantly higher among the 23 crack cocaine users who reported trading sex for money or drugs in the last six months (22.4 vs 8.4; $\mathrm{p}<0.005)$. Of the 46 women $(36.8 \%)$ who reported never having traded sex for money or drugs, 34 $(73.9 \%)$ did so before the age of seventeen.

Seventy-two women (58\%) reported that they had not used condoms in the 30 days prior to the interview, and 65 (52\%) reported they did not carry condoms or keep condoms at home during the same period. A total of $75(60.0 \%)$ interviewees reported never having had a sexual partner who was a drug user.

Thirteen women (10.2\%) reported daily use of crack cocaine and $59(47.0 \%)$ reported smoking crack less than once a week. Regular (daily) use of marijuana in the last 30 days was reported by 69 women (55.2\%), concomitant use of snorted cocaine (at least once in the last 30 days) was reported by five women, and two women reported the use of heroin in the same period.

Current or past diagnoses of sexually transmitted infections (STIs), as reported by the interviewees, as well as information about other ailments/diseases in the last six months, are displayed in Table 2 . The most frequently reported STI was gonorrhea $(10.2 \%)$, followed by genital herpes $(8.7 \%)$, syphilis $(5.5 \%)$ and genital warts/HPV infection (3.9\%). Forty-three interviewees reported having had vaginal discharge in the last six months, $3.1 \%$ reported genital sores and $4.7 \%$ reported sores in the mouth. Pneumonia and tuberculosis were reported by $26.4 \%$ and $5.6 \%$ of participants, respectively.

At the time of the interview, 50 women (40.0\%) reported prior testing for HIV: 30 reported negative results and $20 \mathrm{did}$ not know their serostatus.

Laboratory evaluation revealed low infection rates for different sexually transmitted and/or blood-borne pathogens: two of the 125 women $(1.6 \%$; $95 \%$ CI $0.2-5.7)$ tested positive for $\mathrm{HIV}$; three $(2.4 \%$; $95 \% \mathrm{CI} 0.5-6.9)$ for $\mathrm{HCV}$; one $(0.8 \%$; 95\% CI 0.0-4.4) for HBV (HBsAg); four (3,2\%; $95 \%$ CI 0.98.0) for HTLV-1; one $(0.8 ; 95 \%$ CI 0.0-4.4) for HTLV-2, and five (4\%; 95CI\% 1.3-9.1) for syphilis (as defined by VDRL results) (Table 3).

\section{Discussion}

The impoverished female crack users included in this study displayed several characteristics known to increase susceptibility to different STIs: inconsistent use of condoms (sometimes with multiple partners), networking with other drug
Table 2. History of diagnosed and other STI-related symptoms reported in the last six months among the 125 women crack cocaine users recruited for the study, Salvador, Bahia 20012002

\begin{tabular}{lcc}
\hline Ever diagnosed diseases & N & \% \\
\hline Syphilis & 7 & $5.6 \%$ \\
Gonorrhea & 13 & $10.4 \%$ \\
Genital herpes & 11 & $8.8 \%$ \\
Genital wart & 5 & $4 \%$ \\
Hepatitis & 10 & $8 \%$ \\
Pneumonia & 33 & $26.4 \%$ \\
Pulmonary tuberculosis & 7 & $5.6 \%$ \\
Symptoms and signs of STI in the & & \\
$\quad$ last six months & & \\
Vaginal discharge & 55 & $43.3 \%$ \\
Genital sore & 4 & $3.1 \%$ \\
Mouth sore & 6 & $4.7 \%$ \\
\hline
\end{tabular}

Table 3. Seroprevalence of HIV, HTLV, hepatitis B, hepatitis C and syphilis among the 125 female crack cocaine users recruited for the study, Salvador, Bahia 2001-2002

\begin{tabular}{lcc}
\hline Serological exam & $\mathbf{N}(\boldsymbol{\%})$ & $\mathbf{9 5 \%}$ IC \\
\hline HIV & $2(1.6)$ & $0.2-5.7$ \\
HTLV-1 & $4(3.2)$ & $0.9-8.0$ \\
HTLV-2 & $1(0.8)$ & $0.0-4.4$ \\
Hepatitis B & $1(0.8)$ & $0.0-4.4$ \\
Hepatitis C & $3(2.4)$ & $0.5-6.9$ \\
Syphilis & $5(4.0)$ & $1.3-9.1$ \\
\hline
\end{tabular}

users (as suggested by reported sexual partnerships and trading sex for drugs), and payment for sex. In addition, the subjects were characterized by poverty, unemployment and low educational level. Despite this combination of risky behaviors and "social vulnerability" resulting from dire poverty, infection rates for different pathogens were found to be quite low in comparison to those reported in other vulnerable populations.

HTLV-1 was the most prevalent viral infection in our sample (3.2\%), and was more prevalent than in representative samples of the general population $(1.76 \%)$ and female population of Salvador (2.0\%) [37]. HTLV-1 infection is a public health priority in Salvador, where HTLV-1 is more prevalent among blood donors than in any other Brazilian city [38]. High HTLV infection rates are associated with low socioeconomic status in Salvador, especially among women, and an estimated 40,000 individuals are living with HTLV-1 [37]. HTLV-1 infection rates have also been found to be high (35.2\%) among injection drug users (IDUs) in Salvador [39]. The moderately high prevalence found in this study (4\%) may reflect infections acquired through unprotected sex with male partners that have a high background prevalence of HTLV, since the neighborhoods assessed by the present 
study have pockets where IDUs congregate and that are plagued by endemic poverty, unemployment, and high prevalence of HTLV [37].

The HIV prevalence (1.6\%) in our patients was higher than estimates for the general Brazilian population (0.47\%) [40], but was significantly lower than the prevalence among IDUs $(7.1 \%)$ recruited in the same neighborhood of Salvador [41], and also significantly lower than HIV prevalence identified by previous studies carried out in at-risk populations such as non-injecting drug users from the city of São Paulo (11\%) [42] and commercial sex workers from Santos, São Paulo (8.3\%) [26]. These differences are probably due to the fact that drug users are at higher risk for contracting HIV, and the latter two studies were conducted in two cities in the State of São Paulo, where AIDS incidence in 2001 and 2002 was much higher than in the State of Bahia (26.1 and 27.6/100,000 versus 3.8 and 4.9/ 100,000 inhabitants, respectively) [3].

Successful "harm-reduction" initiatives and declining infection rates for different pathogens such as HIV, HBV and $\mathrm{HCV}$ have been described in different Brazilian cities, such as Santos and Rio de Janeiro [43-46], and an array of other projects have aimed to reduce drug-related harm, with an emphasis on impoverished women at-risk for STIs and blood-borne infections: ample distribution of condoms, on-site counseling and referral for testing and treatment [41]. These programs have most likely had a favorable impact on this high-risk population and helped to curb the spread of different infections, especially HIV. The neighborhoods from which interviewees were recruited for this study belong to the core neighborhoods targeted by the different "harm-reduction" initiatives implemented in the city.

For the sake of a broader, international, comparison, the prevalence of HIV in our population was considerably lower than those found in studies conducted in North American cities. For example, crack cocaine users from 16 American cities and San Juan (Puerto Rico) demonstrated overall HIV prevalence of $7.5 \%$ in the early 1990's [47], and the mean HIV prevalence from other studies carried out in New York city, Miami and San Francisco was 16\% [5]. Of those cities, only San Francisco had a prevalence similar to the one we found [48,49]. However, participants of these studies had higher prevalence of other risk factors for HIV (including injection drug use, incarceration, rape, and higher intensity of crack cocaine use) than our population. The intensity of crack cocaine use has also been shown to be conducive to risky sexual behaviors [32]; therefore, the low intensity of crack cocaine use in our study, which is compatible with a more controlled use of crack cocaine, could be associated with fewer risky sexual activities associated with HIV infection.

Roughly one-third of the interviewees in our study reported having exchanged sex for money/drugs. This proportion is significantly higher than that (13\%) found in 255 patients of both sexes from São Paulo who reported using powder cocaine, either by snorting or by injection [42], but is much lower than the one found in a large NIDA-sponsored study comprising
4,667 female crack users, where the exchange of sex for money and drugs was reported by $57 \%$ of the interviewees [17].

The prevalence of gonorrhea found in our study was approximately two times higher than that (5.8\%) found in a study of inpatients from two major drug treatment centers in Rio de Janeiro [50]. On the other hand, the prevalence of syphilis was almost the same in both studies. The infection rates for gonorrhea and syphilis, as well as the number of reported episodes of herpes and genital warts found in the current study, are higher than those reported among female crack cocaine users attending community and HIV treatment centers in the US [16,34].

The disquietingly high prevalence of self-reported gynecologic problems in our interviewees most probably reflects gaps and deficiencies in Salvador's health care system. So far, the comprehensive "Programa de Saúde da Família" (Family Health Program), the Brazilian Ministry of Health's key strategy for improving access and standards of care for underserved communities, has reached only a small percentage of the Salvador population, with an estimated coverage of 131,146 inhabitants, corresponding to $5.4 \%$ of a total population of $2,443,107$, most of whom live in impoverished communities [51].

The high prevalence of self-reported pneumonia may be linked either to non-hygienic crack smoking practices or to the commonly reported home-preparation of crack cocaine, which uses kerosene, gasoline and ammonia [52]. Tuberculosis is prevalent in Salvador, with a high incidence rate of 120.4/100,000 in 2001 [51]. Although a higher risk for tuberculosis infection among crack cocaine users has been reported [53,54], detailed studies should be performed in order to clarify the high selfreported prevalence of tuberculosis by our interviewees.

The observed seroprevalence of HCV infection corresponds to what we would expect from a population with a low number of injecting drug users [55]. Likewise, the low prevalence of HBV infection is in accordance with the low prevalence of HIV, since our patients are exposed to sexual (but not parenteral) risks, as well as with the declining rates of HBV circulating in Brazil previously reported [56-58]. The fact that a high proportion of women in this study had already been tested for HIV is the result of both CETAD's Harm Reduction Program and the enrollment of these women in previous research projects. Women who reported not knowing the result of prior HIV tests results may be afraid of facing a serious and stigmatizing infection, or may fear having their serostatus disclosed by health workers, researchers or acquaintances living nearby.

Our study found low infection rates for HIV, hepatitis B, and hepatitis $\mathrm{C}$ in an impoverished population engaged in risky sexual behavior. The probable association of such auspicious findings with the consistent implementation of initiatives for reducing the spread of such viruses and other drug-related harm reinforces the need to maintain and increase the scope of such programs, tailoring them to the specific needs of each population. 
The patients highlighted by the present study have urgent need for prevention and proper care of pneumonia and tuberculosis, comprehensive management of gynecologic complaints and common STIs, such as gonorrhea and syphilis; psychosocial support and referral for drug treatment; and, last but not least, social promotion and community development targeting such impoverished and underserved population. As a result, the low prevalence of HIV, HCV and HBV infections should not be viewed with complacency because poverty and risky sexual behaviors still challenge such young women, but rather as a golden opportunity to redirect preventive strategies and to maintain ongoing initiatives with renewed emphasis.

\section{Limitations of the Research}

1. The crack users women recruited in this study were living in neighborhoods where traditional harm reduction programs are already implemented. This fact may explain the low prevalence of infections. On the opposite, in the neighborhoods where such programs do not exist, the rates may be higher.

2. The number of women included in our study is small due to time and budget limitations.

3. Though the amount for transportation and snack is low, it may cause a bias as some recruited women may have reported the use of crack only to receive this money.

4. Crack use was not quantified by blood or urine toxicological tests. It was reported by the women themselves.

\section{Acknowledgments}

Ceuci Nunes is a Post-graduate fellow in Medicine and Health - School of Medicine, Federal University of Bahia. This research was partially supported by Brazilian Ministry of Education (CAPES). We thank Mr. Noilson Gonçalves and Maria Alice Carvalho (Couto Maia Hospital welfare work) for technical and administrative support.

\section{References}

1. Joint United Program on HIV/AIDS [UNAIDS] and World Health Organization [WHO] 2004. Report on the global AIDS epidemic. Retrieved September 19, 2004 from http://www.unaids.org.

2. Brasil. Ministério da Saúde. Aids no Brasil: um esforço conjunto governo-sociedade. Coordenação Nacional de DST e Aids Brasília, 106p. 1998.

3. Brasil. Ministério da Saúde (2004). Boletim Epidemiológico AIDS. Ano XVII n ${ }^{\circ} 01-01$ a 52 semanas epidemiológicas janeiro a dezembro de 2003. Retrieved October 14, 2004, from http:// www.aids.gov.br

4. Smart R.G. Crack Cocaine use in Canada: a new epidemic? Am J Epidemiol 1988;127(6):1315-17.

5. Edlin B.R., Irving K.L., Faruque S., et al. Intersecting epidemics crack- cocaine use and HIV infection among inner-city young adults. New Engl J Med 1994;331(21):1422-7.

6. Andrade T., Lurie P., Medina M.G., et al. The opening of South America's first needle exchange program and an epidemic of crack cocaine use in Salvador, Bahia-Brazil. AIDS and Behavior 2001a;5(1):51-64.
7. Faruque S., Edlin B.R., McCoy C.B.Crack cocaine smoking and oral sores in three inner-city neighborhoods. J Acq Immun Def Synd 1996;13(1):87-92.

8. Inciardi J.A. Crack cocaine in the Americas. M.G. Monteiro and J.A. Inciardi (Eds). Sao Paulo: CEBRID - Centro Brasileiro de Informações sobre Drogas Psicotrópicas (Brazilian Center for Information about Psychotropic Drugs), 1993, Brazil-United States: Binational Research pp. 63-75.

9. Dunn J., Laranjeira R.R. Cocaine - profiles, drug histories, and patterns use of patients from Brazil. Subst Use Misuse 1999;34(11): $1527-48$.

10. Nappo A.S., Galduróz J.C.F., Noto A.R. Uso do crack em São Paulo: fenômeno emergente? Revista ABP-APAL/ Associação Brasileira de Psiquiatria e Asociacion Psiquiatrica de América Latina 1994; $16(2): 75-83$.

11. Nappo A.S., Galduróz J.C.F., Noto A.R. Crack use in Sao Paulo. Subst Use Misuse 1996;31(5):565-79.

12. Booth R.E., Watters J.K., Chitwood D.D. HIV risk-related sex behaviors among injection drug user, crack smokers, and injection drug user who smoke crack. Am J Public Health 1993;83(8) 1144-8.

13. Word C.O., Bowser B. Background to crack cocaine addiction and HIV high-risk behavior: the next epidemic. Am J Drug Alcohol Abuse 1997;23(1):67-77.

14. Semaan S., Kotranski L., Collier K., et al. Temporal trends in HIV risk behaviors of out-of-treatment injection drug users and injection drug users who smoke crack. J Acq Immun Def Synd 1998; $19: 274-81$.

15. Tortu S., McCoy H.V., Beardsley M., et al. Predictors of HIV infection among women drug users in New York and Miami. Women Health 1998a;27(1-2):191-204.

16. Wilson T., DeHovitz J.A. STDs, HIV, and crack cocaine: a review. AIDS Patient Care STDs 1997;11(2):62-6.

17. Logan T.K., Leukefeld C., Farabee D. Sexual and drug use behaviors among female crack users: a multi site sample. Drug Alcohol Depen 2000;58:237-45.

18. Bowen A.M., Williams M., McCoy H.V., McCoy C.B. Crack smokers' intention to use condoms with loved partners: intervention development using the theory of reasoned development using the theory of reasoned action, condom beliefs, and processes of change. AIDS Care 2001;13(5):579-94.

19. Gomez P.M., Kimball A., Orlander H., et al. Epidemic crack cocaine use linked with epidemics of genital ulcer disease and heterosexual HIV infection in the Bahamas. Journal of the American Sexually Transmitted Diseases Association 2002;29(5):259-64.

20. Hudgins R., McCusker J., Stoddart A. Cocaine use and risky injection and sexual behaviors. Drug Alcohol Depen 1995;37(1):7-14.

21. Irwin KL, Edlin BR, Wong L, Faruque S. Urban rape survivors: characteristics and prevalence of human immunodeficiency virus and other sexually transmitted infections. Multicenter Crack Cocaine and HIV Infection Study Team. Obstet Gynecol 1995;85(3):330-6.

22. Heffernan R., Chiasson M.A., Sackoff J.E. HIV risk behaviors among adolescents at a sexually transmitted disease clinic in New York City. J Adolescent Health 1996;18(6):429-34.

23. Eldridge G., St. Lawrence J.S., Little C.E. Evaluation of the HIV risk reduction intervention for women entering inpatient substance abuse treatment. Aids Educ Prev 1997;9(1 Suppl.):62-76.

24. Shuter J., Bell D., Graham D., et al. Rates of and risk factors for trichomoniasis among pregnant inmates in New York City [see comments]. Sex Transm Dis 1998;25(6):303-7.

25. Stevens S.J., Estrada A.L., Estrada B.D. HIV sex and drug risk behavior and behavior change in a national sample of injection drug and crack cocaine-using women. Women Health 1998;27(1-2):25-48.

26. Szwarcwald C.L., Bastos F.I., Gravato N., et al. The relationship of illicit drug use to HIV-infection among commercial sex workers in the city of Santos, Sao Paulo, Brazil. The International Journal of Drug Policy 1998;9(6):427-36. 
27. Wilson T.E., Minkoff H., Dehovitz J., et al. The relationship of cocaine use and human immunodeficiency virus serostatus to incident sexually transmitted diseases among women. Sex Transm Dis 1998;25(2):70.

28. Wingood G.M., Clemente R.J. The influence of psychosocial factors, alcohol, drug use on African-American women's highrisk sexual behavior. Am J Prev Med 1998;15(1):54-9.

29. Tortu S., Goldstein M., Deren S., et al. Urban crack users: gender differences in drug use, HIV risk and health status. Women Health 1998b;27(1-2):177-89.

30. Richard A.J., Bell D.C., Montoya I.D. Normative influence on condom use in the personal networks of female cocaine smokers. AIDS Educ Prev 2000;12(4):357-74.

31. Richard J.R., Bell D.C., Montoya I.D. Age and HIV risk in a national sample of injection drug and crack cocaine users. Subst Use Misuse 2000;35(10):1385-1404.

32. Hoffman J.A., Klein H., Eber M., Crosby H. Frequency and intensity of crack use as predictors of women's involvement in HIV - related sexual risk behaviors. Drug Alcohol Depen 2000; $58: 227-36$.

33. Kalichman S.C., Rompa D., Cage M. Sexually Transmitted Infection Among HIV Seropositive Men and Women. Sex Transm Infect 2000;76:350-4.

34. Hwang L., Ross M.W., Zack C. Prevalence of sexually transmitted infections and associated risk factors among populations of drug abusers. Clin Infect Dis 2000;31(4):920-6.

35. Tortu S., Beardsley M., Deren S. HIV infection and partners of risk among women drug injectors and crack users in low and high seroprevalence sites. AIDS Care 2000;12(1):65-7.

36. Campsmith M.L., Nakashima A.K., Jones L.J. Association between crack cocaine use and high-risk sexual behaviors after HIV diagnosis. J Acq Immun Def Synd 2000;25:192-8.

37. Dourado I., Alcântara L.C.J., Barreto M.L., et al. HTLV-I in the General Population of Salvador, Brazil. A city with African ethnic and sociodemographic characteristics. J Acq Immun Def Synd 2003;34:527-31.

38. Galvão-Castro B., Loures L., Rodrigues L.G.M. Distribution of human T-lymph tropic virus type I among blood donors: a nationwide Brazilian study. Transfusion 1997;37:242.

39. Andrade T.M., Dourado I., Galvão-Castro B. Association among HTLV-I, HTLV-II and HIV in injecting drug users in Salvador, Brazil. J Acq Immun Def Synd 1998;18(2):186-7.

40. Dourado I., Andrade T.M., Galvão-Castro B. HTLV-1 in Northeast Brazil: differences for male and female injecting drug users. J Acq Immun Def Synd 1998; 19:426-9.

41. Szwarcwald C.L., Castilho E.A. Estimated number of HIV-infected individuals aged 15-49 years in Brazil, 1998. Cadernos de Saúde Pública 2000; $16: 135-41$.

42. Andrade T., Dourado M., Farias A.H., Galvão-Castro B. Redução de Danos e redução da prevalência do HIV entre usuarios de drogas injetaveis em Salvador - Bahia. In: A contribuição dos estudos multicêntricos frente a epidemia de HIV/AIDS entre UDI no Brasil - 10 anos de pesquisa de redução de danos. Ministério da Saúde 2001b:114p.

43. Dunn J., Laranjeira R.R. HIV-risk behavior among non-heroin using cocaine injectors and non-injectors in Sao Paulo, Brazil. AIDS Care 2000;12(4):471-81.
44. Mesquita F., Kral A., Reingold A. Trends of HIV infection among injection drug users in Brazil in the 1990s: the impact of changes in patterns of drug use. J Acq Immun Def Synd 2001;28(3):208-302.

45. Teixeira S.L.M., Bastos F.I., Telles P.R. HIV-1 infection among injection and ex-injection drug users of Rio de Janeiro, Brazil: prevalence, estimated incidence and genetic diversity. J Clin Virol 2004;31(3):221-6.

46. Hacker M.A., Friedman S.R., Telles P.R. The role of "long-term" and "new" injectors in a declining HIV/AIDS epidemic in Rio de Janeiro, Brazil. Subst Use Misuse 2005;4(1):99-123.

47. Brasil. Ministério da Saúde (2001). Anuário 2001. Morbidade e fatores de risco. Retrieved February 19, 2003, from http://www. portal.saúde.gov.br.

48. Kral A.H., Bluthenthal R.N., Booth R.E., Watters J.K. HIV seroprevalence among street-recruited injection drug and crack cocaine users in 16 US municipalities. Am J Public Health $1998 ; 88(1): 108-13$.

49. Watters J. Trends in risk behavior and HIV seroprevalence in heterosexual injection drug users in San Francisco, 1986-1992. J Acq Immun Def Synd 1994; 7:126-81.

50. Kral A., Bluthenthal R.L., Lorvick J. Sexual transmission of HIV1 among drug users in San Francisco, USA: risk-factor analysis. Lancet 2001;357:1397-401.

51. Bastos F.I., Lowndes C.M., Castello-Branco L.R. Sexual behavior and infection rates for HIV, blood-borne and sexually transmitted infections among patients attending drug treatment centers in Rio de Janeiro, Brazil. Int J STD AIDS 2000;11(6):383-92.

52. Brasil. Ministério da Saúde. A contribuição dos estudos multicêntricos frente à epidemia de HIV/AIDS entre UDI no Brasil. 10 anos de pesquisa e redução de danos. Brasília: Ministério da Saúde, 114p, 2001.

53. Ferri C.P., Laranjeira R.R., Silveira D.X., et al. Aumento da procura por usuários de crack em dois ambulatórios na cidade de São Paulo, nos anos de 1990 a 1993. Revista da Associação Médica Brasileira 2006; $43: 25-8$.

54. Reyes J.C., Robles R.R., Colon H.M. Mycobacterium tuberculosis infection among crack and injection drug users in San Juan, Puerto Rico. Puerto Rico Health Science Journal 1996; $15(3): 233-6$.

55. Center for Disease Control and Prevention [CDC] (1991). Epidemiology notes and reports crack cocaine use among person with tuberculosis - Contra Costa County, California, 1987-1990. MMWR, 40(29): 485-489. Retrieved February 24, 2002, from http://www.cdc.gov/mmwr/preview

56. Oliveira S.A., Hacker M.A., Oliveira M.L., et al. A window of opportunity: declining rates of hepatitis B virus infection among injection drug users in Rio de Janeiro, and prospects for targeted hepatitis B vaccination. Rev Panam Salud Publica 2005; $18: 271-7$.

57. Fortes H.M., Ribeiro L.C., Perazolo G.F., Souto F.J. Hepatitis B virus screening in contacts of blood donors with antibodies against core protein (anti-HBC), but without surface antigen (HBsAg). Mem Inst Oswaldo Cruz 2006;101:195-7.

58. Rosini N., Mousse D., Spada C., et al. Seroprevalence of HbsAg, Anti-HBc and anti-HCV in Southern Brazil, 1999-2001. Braz J Infect Dis 2003:7:262-7. 